\title{
IMPLICAÇÕES DOS CONSELHOS CONSULTIVOS NA GESTÃO DE UNIDADES DE CONSERVAÇÃO.
}

\section{Helder Henrique de Faria ${ }^{1}$ \\ Andréa Soares Pires ${ }^{1}$}

\begin{abstract}
Resumo: Os Conselhos Consultivos são instâncias de discussão e suporte à tomada de decisões na gestão de unidades de conservação, instituídos por Lei especifica e coordenados pelas organizações gestoras dessas áreas. Neste trabalho são apresentados os conhecimentos adquiridos pelos autores a respeito das implicações dos Conselhos Consultivo na gestão das unidades de conservação, como isto pode influenciar no modus operandi organizacional, que propriedades e características os chefes de áreas protegidas devem possuir na lida diária da gestão participativa. Ademais, discorre-se sobre alguns apontamentos práticos para 0 melhor gerenciamento desta importante instância de discussão e gestão.
\end{abstract}

Palavras-Chave: Conselhos Consultivos. Gestão. Unidades de Conservação.

\section{INTRODUÇÃO}

Nas últimas três décadas ocorreram um aumento considerável no número de áreas protegidas, em razão de um movimento ambiental forte e consciente da necessidade de proteger o patrimônio natural mundial. Mas não basta simplesmente criar uma rede de áreas protegidas para garantir a proteção dos recursos, pois há a necessidade de estabelecer um suporte adequado para sua gestão, questão esta vinculada a diversos

\footnotetext{
${ }^{1}$ Pesquisadores do Instituto Florestal. Parque Estadual do Morro do Diabo, São Paulo. helderdefaria@gmail.com; deapires@yahoo.com.br
} 
aspectos técnicos, políticos e econômicos tais como planejamento, capacidade institucional, conhecimentos gerados e disponíveis, aspectos legais incidentes, programas de desenvolvimento regional, entre outros.

As unidades de conservação (UCs) são definidas no Sistema nacional de unidades de Conservação (BRASIL, 2000) como "espaço territorial e seus recursos ambientais, incluindo as águas jurisdicionais, com características naturais relevantes, legalmente instituído pelo Poder Público, com objetivos de conservação e limites definidos, sob regime especial de administração, ao qual se aplicam garantias adequadas de proteção".

Segundo Faria (2004), a gestão de unidades de conservação (UCs) é "a equilibrada coordenação dos componentes técnicos e operacionais (recursos humanos, materiais, financeiros) e os diversos atores sociais que incidem sobre o desenvolvimento da área, de maneira tal a obter-se a eficácia requerida para se lograr os objetivos para os quais a unidade foi criada e a manutenção da produtividade dos ecossistemas abrangidos". A existência ou ausência destes fatores, assim como a forma como eles se arranjam na organização no tempo e no espaço e como são usados ou aproveitados são determinantes para uma gestão eficaz.

Após a existência da própria área, a gestão eficaz das unidades de conservação é o instrumento mais poderoso para se lograr a conservação da biodiversidade na medida em que garante a permanência da área ao longo do tempo. Dentre as muitas variáveis envolvidas no conceito de 'gestão eficaz', insere-se a participação da sociedade nos desígnios das áreas sob proteção especial como fator preponderante para o alcance dos objetivos de conservação.

No Brasil esse aspecto foi introduzido originalmente na gestão das Áreas de Proteção Ambiental (APAs) e se estendeu a todas as categorias de UCs do país, fundamentalmente após o advento da Lei 9.985, de 18 de Julho de 2000, que instituiu o Sistema Nacional de Unidades de Conservação (BRASIL, 2000), em cujo artigo 29 esta colocado que "cada unidade de conservação do grupo de Proteção Integral disporá de um Conselho Consultivo, presidido pelo órgão responsável por sua administração e constituído por representantes de órgãos públicos, de organizações da sociedade civil, por proprietários de terras localizadas em Refúgio de Vida Silvestre ou Monumento Natural, quando for o 
caso, e, na hipótese prevista no $\S 2^{\circ}$ do art. 42, das populações tradicionais residentes, conforme se dispuser em regulamento e no ato de criação da unidade".

Posteriormente, o Decreto № 4.340, de 22 de agosto de 2002, veio regulamentar alguns artigos da citada Lei, sendo que em relação aos Conselhos Consultivo indica alguns setores que devem constituí-lo, determina o tempo de representação das entidades, o caráter público das reuniões, a competência do órgão coordenador do Conselho, atribuição da organização gestora da UC. Ademais, em seu artigo 20, este decreto estabelece as atribuições gerais do Conselho Consultivo, quais sejam:

I.elaborar o seu regimento interno, no prazo de noventa dias, contados da sua instalação;

II.acompanhar a elaboração, implementação e revisão do Plano de Manejo da unidade de conservação, quando couber, garantindo o seu caráter participativo;

III.buscar a integração da unidade de conservação com as demais unidades e espaços territoriais especialmente protegidos e com o seu entorno;

IV.esforçar-se para compatibilizar os interesses dos diversos segmentos sociais relacionados com a unidade;

V.avaliar o orçamento da unidade e o relatório financeiro anual elaborado pelo órgão executor em relação aos objetivos da unidade de conservação;

VI.opinar, no caso de Conselho Consultivo, ou ratificar, no caso de conselho deliberativo, a contratação e os dispositivos do termo de parceria com OSCIP ${ }^{2}$ na hipótese de gestão compartilhada da unidade;

VII.acompanhar a gestão por OSCIP e recomendar a rescisão do termo de parceria, quando constatada irregularidade;

VIII.manifestar-se sobre obra ou atividade potencialmente causadora de impacto na unidade de conservação, em sua zona de amortecimento, mosaicos ou corredores ecológicos; e

IX.propor diretrizes e ações para compatibilizar, integrar e otimizar a relação com a população do entorno ou do interior da unidade, conforme o caso.

No estado de São Paulo, algumas unidades de conservação já possuíam seus conselhos muito antes do advento dos diplomas legais citados. O mais antigo "Comitê Gestor" provavelmente seja o do Parque Estadual da Ilha do Cardoso, onde as características sócio-ambientais interpuseram tal necessidade. Nos primeiros anos da década de 2000 várias UCs beneficiadas pelo Projeto de Preservação da Mata AtlânticaPPMA, sob os auspícios do banco alemão KFW, tiveram seus Conselhos Consultivos 
formados como uma exigência dos gerentes do Projeto, que desejavam o efetivo envolvimento da comunidade em seus desígnios.

A partir das experiências de campo dos chefes das unidades de conservação, dos pesquisadores e técnicos da Secretaria de Estado do Meio Ambiente, que durante pelo menos 3 anos debateram o assunto, foi editado o Decreto № 49.672, de 6 de junho de 2005, que "dispõe sobre a criação dos Conselhos Consultivo das Unidades de Conservação de Proteção Integral do Estado de São Paulo, define sua composição e as diretrizes para seu funcionamento". Neste documento é possível observar que vários dos artigos nele contido são oriundos de antigos regimentos e estatutos de "comitês" préexistentes, o que vem a corroborar a idéia de que o mesmo está respaldado pelos saberes das bases, os gestores das UCs.

Este trabalho é um artigo de posição que discorre sobre as observações realizadas pelos autores durante visitas técnicas a unidades de conservação paulistas, oportunidades em que se apropriaram das percepções e aprendizados dos gestores em relação ao tema, além da própria experiência de gerir uma unidade com conselho formado e ativo.

\section{CONSELHO CONSULTIVO E GESTÃO DE UC}

A introdução da necessidade de consulta pública no processo de criação das unidades de conservação e a instituição de uma instância de discussão e debates na sua rotina administrativa, através dos Conselhos Consultivos, foram avanços consideráveis em termos da participação comunitária na gestão, sobretudo por que esse mecanismo de gestão deve ser um agente facilitador para a melhoria da qualidade ambiental do entorno dessas áreas, ou dos próprios recursos sob proteção quando há gente vivendo dentro da UC, e, portanto, pode garantir a permanência dessas áreas em longo prazo. No caso de algumas categorias de manejo isto implica na divisão direta da responsabilidade da gestão, como nas reservas extrativistas, mas mesmo naquelas categorias em que o conselho tem caráter apenas consultivo, como nos parques, a geração de co-responsabilidade e apoio é um fato inegável.

${ }^{2}$ OSCIP - organização da sociedade civil de interesse público. 
Se por um lado a legislação é uma premissa necessária, mais ainda é conduzir a conservação da natureza usando-se os artifícios e as ferramentas administrativas e científicas disponíveis, executando assim o que se propala nos meios técnicos como sendo o manejo adaptativo ou adaptável, uma forma de gerenciar os recursos considerando o conhecimento acumulado e as diversas situações conjunturais antepostas às unidades de conservação (Agee, 1996 p.36).

Neste sentido, deve-se encarar a gestão como um experimento de médio a longo prazo, sujeito tanto ao fracasso quanto ao sucesso, no qual o inventário, monitoramento e a pesquisa interagem para o referendo ou não de hipóteses testáveis, em última análise os próprios objetivos de conservação (Halvorson, 1996 p.22). O modelo conceitual do processo interativo do manejo adaptável dá ênfase especial às tarefas de monitoramento e sistemáticas avaliações para a retro-alimentação das decisões, ação recomendável se realizar sempre que possível no âmbito dos CCs.

A regulamentação de alguns artigos da Lei do SNUC pelo Decreto 4.340, de 22 de agosto de 2002 é outro aspecto que vem a apoiar e melhorar a prática da gestão ou manejo adaptável pelo fato de ressaltar a importância da participação da sociedade através dos Conselhos Consultivos na gestão e estabelecer normas estritas para que isto aconteça.

$\mathrm{Na}$ atualidade, é quase consensual a imperiosa razão para que haja a participação de atores externos nos processos de planejamento e gestão (Borrini-Feyerabend, 1997 p.19), que a médio longo prazo verterá benefícios para ambas as partes, o social e o ambiental, devendo-se apenas cuidar para que esta participação não ocorra simplesmente para referendar proposições técnicas exógenas ao sistema produtivo e social local, fatos que podem converter a condição de apoio da comunidade em adversidades e ameaças. Quando a UC possui um Conselho Consultivo representativo, bem orientado e coordenado esses exercícios tendem a fluir de maneira mais tranqüila e objetiva, levando a resultados mais eficazes.

Por outro lado, não se pode dar crédito às afirmações de que a inexistência de plano manejo dificulta a implantação de CC, pois não há aí uma relação de causa e efeito tão direta e lógica. Esta relação pode até existir e estar condicionada a resultados da aplicação de rotinas estatísticas para a co-relação de variáveis, porém seria a mesma coisa que 
afirmar que as UCs do mundo serão extintas porque a maioria não possui planos de manejo (MacKinnon, sd p.irreg.).

Uma importante condicionante é colocada na medida em que um CC bem orientado e coordenado pressupõe que o chefe da UC seja bem capacitado e apto a exercer plenamente seu direito, autoridade e saberes. A constante capacitação de funcionários possibilita vencer muitos dos desafios para a plena conservação da biodiversidade e do patrimônio natural da humanidade, e a série de conflitos e ameaças a que estão sujeitas as áreas protegidas. Arregui e Enei (1995 p. 9) afirmam que os processos de capacitação em todos os níveis de decisão e de trabalho são na atualidade imprescindíveis e de alta prioridade, desde que a temática seja diversificada enfocada no moderno e real, abarcando diferentes vertentes do conhecimento. No caso de Conselhos Consultivos, os administradores precisam ter acesso, experiência e traquejo em relações inter-pessoais para dirimir conflitos que possam aparecer, desde os interesses alheios aos objetivos de gestão das UCs.

Através dos Conselhos pode ocorrer um efetivo reconhecimento sobre a importância das zonas de amortecimento (tampão, de entorno, de influência, de transição, ou qual nome desejem para a mesma), que passarão a ter um papel fundamental nas ações de conservação ao deixarem de ser apenas um traçado no entorno da unidade, mas um poderoso componente de planejamento e manejo que visa minimizar os impactos mútuos entre a área e a vizinhança imediata (Cifuentes, 1992 p. 20).

No âmbito do PE Morro do Diabo, o CC foi instituído alguns meses antes do início do processo de elaboração do plano de manejo, quando a organização responsável era o Instituto Florestal, aspecto que facilitou sobremaneira os trabalhos posteriores. Algumas ameaças foram foco de discussões e de posturas pró-ativas, tais como a questão relativa ao plantio de cana-de-açúcar bem próximo aos limites do Parque. A queima de palha de cana-de-açúcar no entorno das UCs de São Paulo foi generalizadamente tratada pela Lei Estadual № $10.547 / 2000$, que estabeleceu para todas as categorias de manejo paulistas a distância mínima de 50 metros desde os limites da área. Em 2002 a Lei № 11.241 atualizou o cronograma para a eliminação completa do uso do fogo no Estado, com um horizonte máximo de 30 anos e manteve os genéricos 50 metros em relação às Unidades de Conservação. Nesse ínterim, a discussão sobre a questão avançou no CC e resultou 
uma "recomendação" da Promotoria de Justiça e do Meio Ambiente de Presidente Prudente, publicada em Diário Oficial, para que no PEMD os empreendedores observassem uma distância de 1.000 metros para a queima de palhada (DOE, 2002).

Nesta mesma unidade, as discussões foram acaloradas em relação aos atropelamentos de animais silvestres no trecho da SP-613 que segmenta o parque em 14 quilômetros de extensão. Durante anos o problema foi vivenciado pelos gestores e pelo poder público sem que houvesse repercussão favorável à conservação. Na medida em que o tema foi inserido na pauta do CC a indignação tomou conta das pessoas e repercutiu. $\mathrm{O}$ trecho foi definido como zona de uso conflitante no plano de manejo (IF, 2006) e posteriormente foi transformado em "estrada parque", aplicando-se sobre a mesma os conceitos e diretivas do Decreto №53.146, de 20 de junho de 2008, que define os parâmetros para a implantação, gestão e operação de estradas no interior de unidades de conservação de proteção integral no Estado de São Paulo (Faria e Pires, 2012).

Este conselho funcionou por 10 anos, com renovações a cada 2 anos, e deixou de funcionar com a mudança de gestores patrocinada pela Fundação Florestal em 2012. Na atualidade o PEMD não possui Conselho Consultivo e não há nenhuma iniciativa para tal, ainda que estejam previstas grandes obras a serem edificadas na unidade, desconsiderando totalmente a atribuição 8 do Decreto № 4.340/2002.

Em 2010 no PE Aguapeí a postura adotada pelo Conselho Consultivo foi determinante na desaprovação de uma proposta de construção de uma unidade prisional no interior da zona de amortecimento do Parque, mesmo que o gestor apresentasse receios do que porventura pudesse acontecer com ele, demonstrando que gestores indecisos podem ser auxiliados pela força política da sociedade.

No PE Ilha do Cardoso, uma das mais belas áreas protegidas de São Paulo, para administrar-se o conflito de possuir gente no interior da unidade a chefia adotou como estratégia de gestão a criação de um Comitê de Apoio à Gestão, talvez uns dos mais antigos da categoria em funcionamento. Ao todo o parque abriga quase 200 unidades familiares que vivem da pesca, agricultura de subsistência e a exploração da caxeta (permitido somente às famílias tradicionais). O comitê reunia-se mensalmente para tratar de todas as questões relativas ao manejo do Parque que envolvesse os interesses da comunidade, deliberando-se sobre reformas e ampliações de residências, novas 
construções, energia, saneamento, corte de árvores para canoas, área de cultivo mínimo, etc. Alguns teóricos vêem nisso sinais de abandono da área pelo Estado ou desobediência legal, porém as pessoas estavam lá há muito e a UC chegou; para que o conflito não se transforme em ameaça real nada melhor que envolver as pessoas na gestão daquilo do qual elas dependem e amam.

Também ali a Fundação Florestal promoveu mudanças radicais nos dois últimos anos, afastando gestores com alta capacidade técnica e inserção efetiva na vida local para iniciar o que denominamos 'experimentos' com gestores novos e sem experiência (O Estado de São Paulo, 2013a). Isto poderá desencadear conflitos maiores, haja vista que o ecoturismo é uma das fontes de renda daquelas famílias, mas a organização responsável possui planos de terceirização dos serviços de uso público que colidem com os justos interesses dos caiçaras.

Os Conselhos Consultivos abrem amplas perspectivas e é a conduta ideal para a gestão eficiente da coisa pública, facilitadora da gestão bioregional, que proporciona a descentralização das decisões através do planejamento e gestão participativas (Miller, 1996 p.42,43 e 44). Eles são palco e um fator para a constante capacitação das pessoas nele envolvidas, mas fundamentalmente impele os funcionários das UCs a buscarem treinamento sobre os temas demandados pelas ações de gestão e manejo discutidas no âmbito desta instância. Também torna as administrações mais transparentes e as instituições, outrora pouco ou nada conhecidas regionalmente, detentoras de uma responsabilidade maior frente ao desafio de se fazer representar, e bem, junto à sociedade. Conseqüência imaginável do funcionamento efetivo de Conselho Consultivo é o aprofundamento dos conhecimentos dos técnicos das UCs em relação às questões sócioambientais e, provavelmente, uma maior e melhor tomada de posição frente às demandas locais.

Tudo indicava que a filosofia que norteou a proposição, criação e implementação dos Conselhos Consultivos seria adotada também pelas organizações de Estado, tornando-as mais democráticas, mediante mecanismos promotores de envolvimento e participação das suas comunidades internas. Pelo menos em relação à Fundação Florestal, em São Paulo, isto não aconteceu, ou melhor, foi promovido durante curto tempo em que imperou uma 
gestão pró-ativa (2007-2010), mas não desencadeou mudanças significativas na estrutura organizacional, mantendo-se o modus operandi tecnocrático e centralizador.

Poderiam as organizações avançar rumo à modernidade gerencial de que tanto necessitam, com os gestores das UC fazendo parte efetiva da estrutura administrativa, como grupo social organizacional e agentes dos canais de comunicação e de decisão, quiçá participantes da formulação de políticas e diretrizes institucionais, fatores que, segundo Bergamini (1997p.123), torna o trabalho das pessoas mais agradável e são pílulas de motivação constante. Senão vejamos, o que acontece ao espírito de um jovem chefe de UC, com elevada motivação para a gestão participativa, que encara isto não como um desafio, mas uma oportunidade e mecanismo facilitador inserido em uma Instituição onde ele é alijado da tomada de decisão sobre os rumos dele mesmo?

A rapidez do processo decisório e a capacidade do fazer acontecer consistem em dois dos principais atributos da rota do sucesso de qualquer empreendimento (Junqueira e Vianna, 1996 p.134), os quais estão relacionados à capacidade de antecipar tendências futuras e obter apoio para as ações necessárias à gestão. O impacto deste cenário, juntamente com o funcionamento dos Conselhos Consultivo deveria resultar numa tomada de consciência por parte dos dirigentes, exigindo que escritórios centrais e gestores das UCs tivessem um relacionamento muito mais estreito para um processo decisório consistente e coerente com a realidade.

Pois uma das grandes dicotomias das organizações neste final de século provavelmente seja a disparidade entre o conteúdo das mudanças que ocorrem no ambiente externo e a velocidade de respostas que surgem no seu ambiente interno. Parece que muitas vezes os dirigentes pensam que as modificações e reversões representam fenômenos que só existem fora das organizações, não tendo uma ligação mais forte com a estrutura do pensar e do agir (Junqueira e Vianna, 1996 p. 134,135).

Os Conselhos Consultivos são mais uma das manifestações de uma sociedade carente de mecanismos democráticos, uma nação que corre a passadas largas em direção ao pleno exercício da cidadania, um modelo que as organizações de Estado deveriam aproveitar, aprimorar e internalizar, caso contrário as insatisfações e frustrações serão demasiadas internamente. 
Dentro deste quadro urge surgir, efetivamente, uma organização reflexiva, aquela que procura se desenvolver através da idéia de "aprender fazendo", o que requer uma permanente atenção sobre os resultados das ações e uma grande disposição para analisar criticamente os erros e acertos através do monitoramento constante das ações (Dudley \& Imbach, sd p.irreg.). Uma organização composta por pessoal capacitado e dirigentes próativos, entusiastas, comprometidos, humanos, motivadores, com vontade de aprender, prazer de ensinar, visão estratégica, empreendedor, assertivo e ético (Junqueira \& Vianna, 1996 p.150-167). Organização que será capitaneada pela motivação verdadeira, aspectos que todos aguardam no sistema de unidades de conservação de São Paulo (Quadro 1).

\section{Quadro 1. Requisitos gerenciais para uma organização reflexiva.}

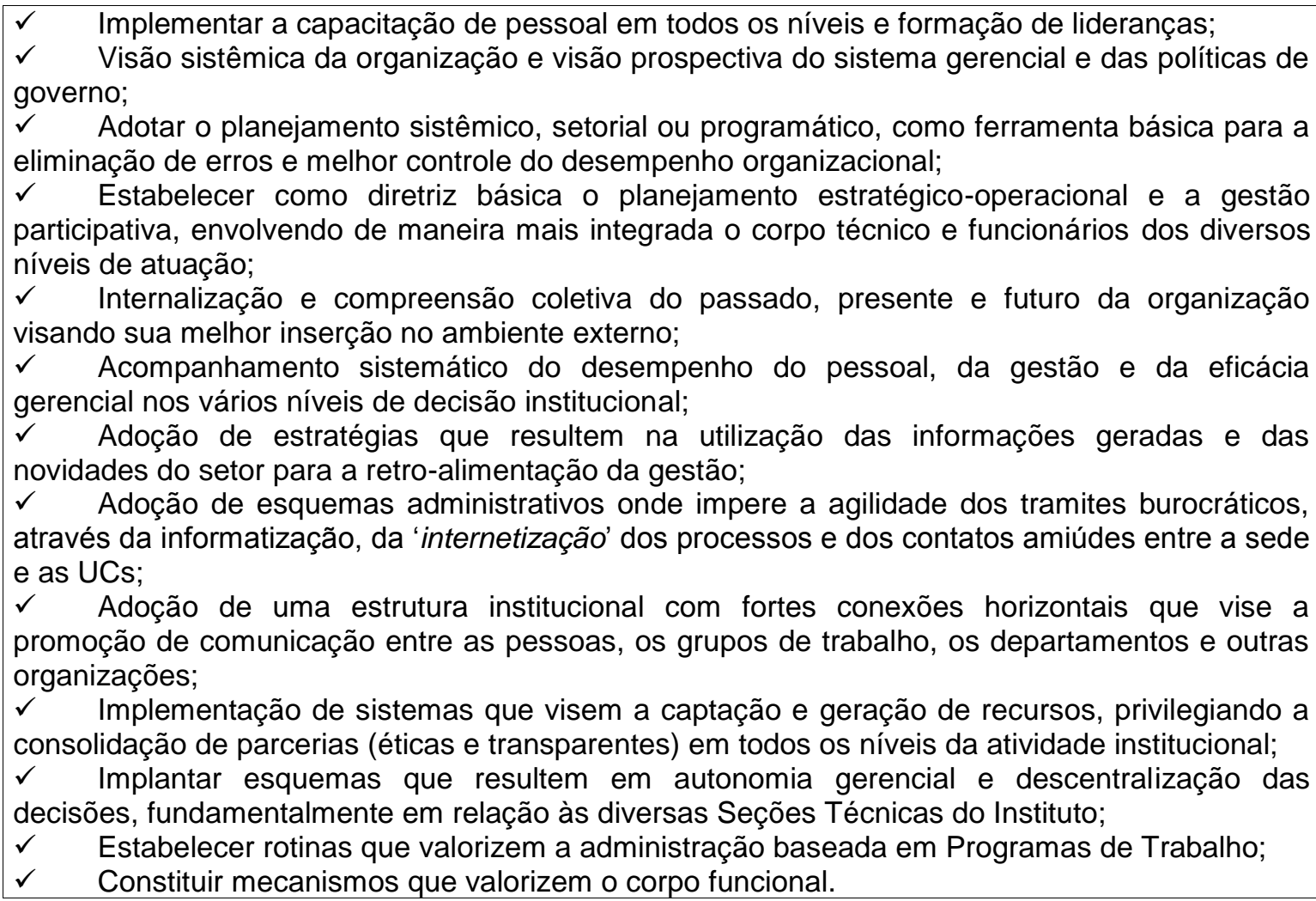

Adaptado de Lucena (1992); Grumbine citado por Agee (1996); Junqueira \& Vianna, (1996); Bergamine (1997); Dudley \& Imbach, (sd).

\section{CONSELHO CONSULTIVO E PERFIL DO GESTOR DE UC}


Os chefes de UCs estão diante de um grande desafio e oportunidade com o advento dos Conselhos Consultivo, e para que eles se saiam bem e as unidades ganhem com a gestão participativa é necessário, antes de tudo, capacitação e treinamento dirigido ao trato com pessoas e organizações das mais diferentes índoles e interesses. Isto é o mais necessário e inquestionável atributo do técnico de ponta neste modelo de gestão, pois parece haver uma relação bastante direta entre a qualidade das ações de gestão e as características pessoais e profissionais dos diretores das unidades de conservação, aspecto este dependente de alguns poucos fatores além, evidentemente, da formação acadêmica superior, que preferencialmente deve se situar na área ambiental.

$\mathrm{Na}$ atualidade não importa muito qual a afiliação especifica dos gestores de UCs, se são biólogos, ecólogos, engenheiros florestais e agrônomos, geógrafos, oceanógrafos ou outra do gênero, pois há muito as profissões deixaram de ser um bom parâmetro para julgar quem é ou será um bom ou mau gestor. Isso depende muito da personalidade e do caráter do profissional, mas existem casos que devem ser encarados como exceções importantes, haja vista que o gestor do Parque Estadual de Carlos Botelho é um Engenheiro Civil Sanitarista cuja performance não perde para nenhum profissional da área ambiental. Mesmo porque hoje ocorre uma verdadeira revolução dos conhecimentos, promovida pela disponibilidade e acessibilidade de informações via Internet.

O perfil de um gestor de unidades de conservação é moldado, em primeiro lugar, pela capacitação formal e informal adquirida sobre manejo e gestão de recursos naturais renováveis, principalmente para formas adaptativas de tratamento e intervenção nos problemas e nos fatores inerentes à gestão de UCs, no caso presente para o melhor desenvolvimento das relações interpessoais e organizacionais. Esta capacitação ocorre também na medida em que há troca permanente de idéias e de experiências entre as pessoas integrantes do sistema gerencial, sobre a atuação frente aos Conselhos Consultivos e suas particularidades, sendo de fundamental relevância que as organizações possuam dentre seus programas estratégicos aquele(s) voltado para uma efetiva participação de seus quadros em cursos e eventos de caráter sócio-ambientais.

O segundo fator importante é a experiência adquirida no front da conservação da natureza, mediante o envolvimento do técnico com os assuntos e problemáticas locais, na 
tentativa de fazer com que a UC esteja inserida na cultura e no desenvolvimento regional, aplicando conhecimentos e as diretrizes para um manejo integrado e bio-regional.

Apesar de haverem diretores com até certo grau de capacitação e experiência, com boas idéias, propostas e projetos, estas em alguns momentos podem não sair do papel, pois há um terceiro fator que os empurra contrariamente que é a (falta de) motivação para a projeção de metas e a realização de ações de gestão de inegável efeito (se forem levadas adiante). Uma pessoa desmotivada é parcialmente morta, e o que é pior, contamina o ambiente de trabalho. Para os diretores de UCs a (des)motivação pode estar relacionada a três pontos principais: a inexistência de mínimas condições de trabalho, a ausência de uma carreira e salários compatíveis e o seu não envolvimento nos objetivos, metas e vida da organização.

As condições de trabalho aqui apontadas referem-se aos meios necessários para a realização das tarefas cotidianas. Não há como pedir que um profissional elabore um projeto e o execute sem que o mesmo tenha disponíveis computadores, veículos, sistemas de comunicação, sem falar de pessoal adequado e treinado para as funções inerentes ao desenvolvimento dos objetivos e metas. Este componente da motivação individual e coletiva deve ser encarado como essenciais à própria existência das áreas protegidas, dependentes de iniciativas integradas e do esforço organizacional coletivo e participativo, procurando caminhos alternativos para suprir as demandas impostas pela modernidade.

O segundo componente é um pouco mais difícil de ser corrigido pela organização isoladamente e, assim, a existência de desmotivação em razão de baixos salários, carreiras inadequadas ou simplesmente a inexistência de um rol de cargos e salários compatíveis é um problema cujas soluções estão ou nas pressões políticas ou nas judiciais. A Fundação Florestal, atual responsável pela gestão das UCs paulistas, mantém um sem número de gestores e outros cargos sem concurso público, os denominados 'cargos comissionados'. Possui 408 funcionários concursados e 105 comissionados, estes últimos na função de gestores e assessores (O Estado de São Paulo, 2013a). Agrava o fato de haver indícios de a seleção dos gestores comissionados não ser criteriosa, sem considerar currículo na área de conservação ou gestão ambiental e o mérito profissional (O Estado de São Paulo, 2013b). 
Isto resultou na sua condenação, pela Justiça do Trabalho, a pagar $\mathrm{R} \$ 500$ mil em danos morais coletivos, declarando nulos os contratos em cargos comissionados para as atribuições de secretária, assistente jurídico e direção sem concurso público. Se a Floresp não cumprir a decisão no prazo de 12 meses terá de pagar multa diária de $R \$ 10$ mil por trabalhador mantido irregularmente (MPT, 2013).

Isso poderia ser evitado se a Fundação Florestal mantivesse uma postura mais técnica e procurasse abrir carreira e concurso para gestores de UCs, dado que a seleção dos 'comissionados' não garante a lisura e a idoneidade que os processos inerentes à administração da coisa pública requerem.

A desmotivação em razão do não enquadramento, da não participação e envolvimento dos profissionais nos objetivos da organização geralmente é a conseqüência do 'abandono e esquecimento' a que estão sujeitos por parte da mesma organização. Provavelmente isto seja um dos problemas mais graves das organizações que não praticam a reflexão interna, e demonstra o tamanho do equívoco em que se enfiam por não possuir diretrizes concretas e amplas que abarquem o componente 'valorização profissional'.

Isto acontece com freqüência porque não há entendimento de que o indivíduo é quem faz acontecer e é o mais importante, a ponta da linha de um seguimento social que trata de estabelecer as bases para a conservação, a longo termo, da biodiversidade em suas mais complexas relações com a sociedade e, portanto, não podem ser simplesmente olvidados ou abandonados à própria sorte. Eles precisam ser resgatados e acompanhados, participar na formulação de políticas e compor efetivamente os canais de comunicação da organização para que se sintam úteis na estrutura administrativa, pois a construção de uma organização forte passa necessariamente pela valorização dos seus recursos humanos, sendo imprescindível ao soerguimento de quaisquer delas, independente do seu estágio de desenvolvimento.

Frente a estas questões é pouco provável afirmar, de modo simplista e leviano, que existam gestores ruins, que ameaçam as unidades de conservação tal qual alguns autores insistem em discursar. Há sim aqueles mal selecionados, despreparados para a função que exercem, os desmotivados em função do 'abandono' pela organização, aqueles que 
não estão no lugar certo. Cabe às organizações saber trabalhar estes fatores, pois dela é a responsabilidade maior.

Relativo à gestão e ao funcionamento dos CCs, importa se os chefes de UCs conduzem suas tarefas de modo condizente com as políticas delineadas para o sistema, preferencialmente com eficácia e sucesso. E que sejam engajados nas políticas conservacionistas locais. Mas, tal qual já mencionamos, eles precisam, sobretudo, de capacitação, pois nenhum deles fez psicologia e não estão afeitos, em sua maioria, a tratar e dividir os problemas e as ameaças das UCs com seus vizinhos e as diversas organizações locais e regionais.

\section{APONTAMENTOS PRAGMÁtICOS PARA A GESTÃO DE CONSELHOS CONSULTIVOS}

Com base no funcionamento do Conselho Consultivo do Parque Estadual do Morro do Diabo, unidade localizada nas coordenadas geográficas $22^{\circ} 27^{\prime}$ a $22^{\circ} 40^{\prime}$ de Latitude S e $52^{\circ} 10^{\prime}$ a $52^{\circ} 22^{\prime}$ de Longitude $W$, e no conhecimento de fatos e experiencias de outras UCs paulistas, apresenta-se a seguir alguns apontamentos e sugestões para que os chefes das unidades considerem no transcurso da criação e condução destas instâncias de discussão.

- Não fazendo apologia à desobediência legal, não adianta as organizações empreenderem um grande esforço para que todas as UCs possuam seus Conselhos. A realidade do território no qual ela se insere tem que demandar essa instância, caso contrário ele será criado e se tornará um conselho de papel, ao invés da instância democrática esperada.

- O chefe da UC precisa perceber esta realidade e desejar, querer e ter ciência do desafio que é implantar um CC, caso contrário porque investir nisso? Para simplesmente cumprir com uma obrigação legal? Para tanto ele precisa possuir um mínimo de experiência nas lides da gestão, conhecer minimamente as variáveis em jogo, conhecer os atores externos que tenham relação com a área, além de capacitação para melhor tramitar os diversos assuntos a serem abordados neste âmbito. 
- O Chefe da UC e seus técnicos precisam ser os agentes que irão tratar de todos, ou quase todos, os aspectos relacionados à criação e implantação do Conselho Consultivo. Caso ele não tenha perfil para tal, deverá ser treinado e capacitado visando adquirir a segurança necessária para levar adiante a empreitada. Salvo condições muito especiais, isso não deve ser levado a cabo por pessoas exógenas ao sistema administrativo local, caso contrário pode-se criar falsas expectativas ou inibir o surgimento de lideranças locais, principalmente do próprio diretor da UC. Nunca se deve permitir a confusão do apoio oferecido pelos escritórios centrais da organização com inaptidão ou falta de habilidade por parte do técnico local.

- O CC precisa possuir objetivos muito claros, estabelecidos no decorrer de discussões com os interessados e definido em Estatuto ou Regimento Interno, sempre associado aos objetivos de gestão da unidade de conservação, o que facilita ao coordenador delimitar muito bem o campo de ação do Conselho. Por outro lado, como os membros são pessoas, é importante que o coordenador reafirme e relembre sempre os objetivos do CC e da UC, assim como da própria organização, evidenciando que o foco é a conservação e o desenvolvimento sócio-ambiental da unidade e seu entorno.

- Deve-se evitar que haja uma procura intensa, pessoal e organizacional, por uma participação no CC, no momento que antecede sua criação, o que é alcançado por um convite objetivo e dirigido àquelas organizações que possuam uma verdadeira interface com a gestão da área. Senão o começo pode ser um atropelo de interesses, prejudiciais à administração mesmo. Como a participação nos CCs é voluntária, o "andar da carruagem", o tempo e a atitude apropriada do coordenador, assim como dos convidados, de conformidade com o Estatuto e toda a legislação que permeia sua atividade, serão os filtros naturais das organizações participantes, reafirmando-se, em todas as oportunidades, que o trabalho em equipe é desafiador e torna as pessoas melhores.

- Portanto, não se deve ter pressa para a instalação de CCs. A aproximação com a comunidade é melhor que aconteça de modo gradual e de acordo com as condições objetivas local, o que possibilita o aparecimento e conhecimento de 
membros engajados nos verdadeiros objetivos de conservação e de desenvolvimento.

- Quando houver várias organizações não governamentais (ongs) na área de influência da UC e que com ela interajam é recomendável que, segundo o Estatuto do CC aprovado por seus integrantes, a vaga se refira a uma representação delas, para que o colegiado não sofra disparidade representativa ou um "inchaço" comprometedor dos seus objetivos que, em primeira instância, é a própria representação democrática da sociedade.

- A coordenação deve incutir nos membros a importância da capacitação interna para crescimento gradual visando a identidade e unidade dessa instância de discussão e decisão. Isto pode e deve ser uma rotina das reuniões do $\mathrm{CC}$, com o agendamento de palestras de, por exemplo, pesquisadores que atuam na UC (selecionar temas que se relacionam com a gestão de fato) e de profissionais da própria organização.

- Na mesma medida, é muito recomendável promover-se o fortalecimento do CC mediante o conhecimento mútuo do papel de cada organização membro e através de resultados práticos de ações desenvolvidas. Assim, é importante que cada organização se apresente através de palestras agendadas no decorrer do tempo, o que permitirá a todos os membros vislumbrar qual o potencial de cada organização em relação à gestão da unidade de conservação.

- Nestes encontros é importante sempre reforçar o papel da organização responsável e sua inserção na estrutura de governo, resgatando sua missão histórica na gestão das UCs do território e, assim, qualificando-a para a gestão local. Convidar e mostrar o pessoal que trabalha nos escritórios centrais é uma estratégia que provê propriedade e suporte adequado à administração local, senão como os membros do CC irão identificar o chefe da unidade e presidente do Conselho? Um solitário e sem amparo?

- O CC não pode ter caráter promocional das organizações ou pessoas participantes. Isto deve ser combatido. Os membros do CC devem internalizar que o papel deles é auxiliar a administração a buscar caminhos mais fáceis para as metas traçadas para a UC e seu entorno, soluções para problemas enfrentados no 
processo de gestão e o combate às ameaças da unidade, pois muitas vezes pode ocorrer que esta ou aquela organização prevaleça neste espaço para a autopromoção.

- A definição dos assuntos a serem abordados nas primeiras reuniões deve ser objeto de cautela por parte do coordenador para que haja equilíbrio nas pautas. Por outro lado, as reuniões do CC não podem ter um clima de "conflito latente", com uma seriedade exacerbada por parte da coordenação e seus membros. Deve-se 'descomplicar' o modo de ser do conselho e, por conseguinte, da própria gestão da UC. A alegria e descontração são componentes importantes e cria um clima de camaradagem e confiança, mesmo que haja diferenças pessoais e/ou de opinião.

- Deve-se procurar ser o máximo possível consensual, evitando-se votações que possam promover divergências internas que, por vezes, causam traumas à administração, pelo menos nos tempos iniciais. Para tanto é interessante que o coordenador conduza discussões sobre temas relevantes, mas que se paute pelo conhecimento dos fatos e matérias tratadas, impedindo-se assim as simples especulações a respeito das decisões a serem tomadas.

- O CC deve ser pró-ativo, uma instância para a discussão dos problemas, ameaças e desenvolvimento da UC, evitando-se a simples cobrança de atitudes por parte da administração. Uma boa estratégia é tentar fazer com que as pessoas entendam a necessidade de trabalhar com propostas programáticas concretas, tais como o desenho de normas de uso para a zona de amortecimento e manejo de zona de uso conflitante; manejo, prevenção e combate a incêndios; tráfico de animais silvestres; projetos com organizações comunitárias do entorno e outras; projetos de pesquisa; solução de conflitos, etc.

- Apesar de no Decreto que regulamenta o SNUC dizer que a unidade deve envidar esforços para a participação de todos os membros, isto não significa que o CC deva ser um ônus para a administração da área. A administração local não pode arcar com custos extras de transportes e cafezinhos, sendo o correto a busca de mecanismos alternativos para financiar as reuniões ou a organização aumentar os recursos destinados a área. 
- A troca de experiências entre CCs de diferentes Unidades de Conservação deve ser prestigiado pela organização gestora, visando aprimorar as técnicas cognitivas e estratégias desenvolvidas, o que diretamente também promove a capacitação das pessoas e uma maior eficiência da integração organizacional.

- Ao final de cada período gerencial, após um ano de trabalho ou o tempo que melhor convier à gerencia da unidade e aos membros do Conselho, é de bom alvitre uma prestação de contas daquilo que se alcançou em função do trabalho coletivo, assim como uma análise transparente das dificuldades e 'nós críticos' ocorridos na gestão da unidade, buscando-se as melhores alternativas que os solucionem e façam materializar as metas no futuro próximo. Com o passar do tempo isto se torna uma prática arraigada na gestão da UC, principalmente se a administração cuidar para que o Conselho Consultivo se envolva no planejamento operativo anual da unidade, propondo e conhecendo as metas programáticas e apoiando-as com propriedade através da sua representatividade social.

- A reestruturação dos Conselhos geralmente acontece a cada 2 anos, sendo este um momento fundamental para uma efetiva reflexão sobre a atuação de todas as organizações participantes buscando-se, através de critérios de ética, transparência e respeito organizacional, uma maior eficácia funcional e colaborativa em prol do alcance dos objetivos do Conselho Consultivo e da própria unidade de conservação.

\section{CONSIDERAÇÕES FINAIS}

Os Conselhos Consultivos estabelecidos pela Lei do SNUC são mecanismos que faltavam para que a gestão participativa decolasse como filosofia de gestão, levando a necessária prática da cidadania às UCs e motivando, inclusive, a formação de agremiações semelhantes para a participação de funcionários na gestão. Esta ferramenta não é a panacéia para a melhoria da eficácia de gestão das áreas protegidas, mas certamente é um fórum onde os questionamentos se aprofundarão e muitas alternativas de gerenciamento podem surgir. 
Pelo mesmo viés, os CC são uma grande onda motivadora de mudanças em relação às políticas de gestão das coisas públicas, abrindo oportunidades não somente para a sociedade, mas também para que o staff das organizações responsáveis pelas UCs questione os modelos de gestão no quais imperam o centralismo das tomadas de decisão. É imaginável que uma organização, um sistema ou sub-sistema de UCs que conte com 10, 20, 50 Conselhos Consultivos funcionando se modernize, pois devemos crer que as organizações assimilarão o que está acontecendo no campo e a gestão participativa interna resultará em oportunidades para transformá-las em organizações reflexivas, onde as opiniões dos que estão na ponta da gestão serão levadas em conta, dentro do melhor espírito de urbanidade que deve eivar essas relações.

Aos chefes de UCs cabe conduzir o bom funcionamento dessas instâncias, entretanto os mesmos devem estar preparados adequadamente para estas tarefas, caso contrário o desastre é certo ao se tentar administrar saberes e comportamentos humanos algumas vezes desconexos dos legítimos objetivos dos Conselhos Consultivos.

As regras devem ser claras, os objetivos esclarecidos e conhecidos, metas bem traçadas e resultados e ganhos compartilhados, pró-atividade em todos os sentidos, sobretudo os administradores de UCs e coordenadores de Conselhos Consultivos devem ter sempre em mente que a função de exercer um cargo público é o de simplesmente zelar das coisas que são públicas, com a eficácia que o sistema e a sociedade exigem.

As razões de existência dos Conselhos Consultivos são: auxiliar no cumprimento dos objetivos de manejo das unidades de conservação, solucionar os interesses coletivos incidentes sobre as áreas e o efetivo exercício da cidadania nos temas relativos à conservação da natureza. Infelizmente as UCs de São Paulo atravessam um período de retrocesso no que diz respeito à participação cidadã e de gestão técnica, provavelmente em função do modelo de gestão instalado a partir de 2011.

\section{REFERENCIAL}

AGEE, James K. Ecosystem management: An Appropriate Concept for Parks? IN: WRIGHT, R. Gerald (Ed.). National Parks and Protected Areas. Their Role in Environmental Protection. Massachusetts, USA. 1996.p. 31-44. 
ARREGUI, Juan V. Oltremari y ENEI, Gisela González. La Capacitación en Matéria de Áreas Protegidas en América Latina. Una Visión general de la situación actual y prioridades futuras. Flora, Fauna y Areas Silvestres. Proyecto FAO/PNUMA. Santiago, Chile. 9(21): 8-11. 1995.

BERGAMINI, Cecília Whitaker. Motivação nas Organizações. $4^{a}$ edição. São Paulo: Ed. Atlas, 1997. 214p.

BORRINI-FEYERABEND, Grazia. Manejo Participativo de Áreas Protegidas: Adaptando o Método ao Contexto. Temas de Politica Social. Quito, Ecuador: UICN Sur.1997. 67p.

BRASIL. Lei $\mathrm{n}^{\circ} 9.985$ de 18 de julho de 2000. Regulamenta o art. 225, § 1ㄹ, incisos I, II, III e VII da Constituição Federal, institui o Sistema Nacional de Unidades de Conservação da Natureza e dá outras providências. Diário Oficial da República Federativa do Brasil. Brasília, 19 de jul. 2000. Seção I. p. 12026-12027.

CIFUENTES, Miguel. Establecimiento y manejo de zonas de amortiguamiento. Revista Forestal Centroamericana. Turrialba, Costa Rica: CATIE, 1992b. 1(1):17-22.

CIFUENTES, Miguel; IZURIETA, Arturo y De FARIA, Helder Henrique. Medición de la efectividad del manejo de áreas protegidas. Serie Tecnica $\mathrm{n} \circ$ 2. Turrialba, Costa Rica: WWF, GTZ, UICN. Forest Innovations Project, 2000.100p.

DIÁRIO OFICIAL DO ESTADO. Recomendação PGJ 870/2002 para que os órgãos ambientais se abstenham de autorizar o emprego de fogo e agrotóxicos em práticas agrícolas, pastoris e florestais no raio de 1000 (mil) metros contados a partir dos limites do Parque Estadual do Morro do Diabo. 14/12/2002. p. 50.

DUDLEY, Eric and IMBACH, Alejandro. Instituciones reflexivas. Ocho caracteristicas de las instituciones que promuevem y pratican el aprender haciendo. 13p. Disponível em www.iucn.org. Acessado em: 06/07/2004.

FARIA, Helder Henrique de; PIRES, Andréa Soares. Rodovia em unidade de conservação: o caso do Parque Estadual do Morro do Diabo, São Paulo, Brasil. VIII Fórum Ambiental da Alta Paulista-Biodiversidade e Unidades de Conservação. Periodico eletrônico v. 8, n. 3, p. 01-22. 2012.

1980-0827.

http://www.amigosdanatureza.org.br/publicacoes/index.php/forum/article/view/274.

HALVORSON, Willian L. 1996. Changes in landscape values and expectations: What do we want and how do we measure it? IN: WRIGHT, R. Gerald (Ed.) National Parks and Protected Areas. Their Role in Environmental Protection. Massachusetts, USA. p. 15-30

JUNQUEIRA, L.A. Costacurta e VIANNA, Marco Aurélio Ferreira. Gerente total: como administrar com eficácia no século XXI. São Paulo, SP: Editora Gerente, 1996. 177p. 
LUCENA, Maria Diva da Salete. Avaliação de desempenho. São Paulo, SP: Ed. Atlas, 1992. 159p.

MacKinnon, J. Avenues of Futility in Conservation. Disponível em http://home.pacbell.net/mjvande/scb5.htm. Acessado em 07/09/2004.

MILLER, Kenton R. Balancing the Scales. Guidelines for Increasing Biodiversity's Chances Througt Bioregional Management. Washington DC: World Resources Institute, 1996. 73p.

MINISTÉRIO PÚBLICO DO TRABALHO. Justiça do Trabalho condena Fundação Florestal em $\quad R \$ \quad 500 \quad$ mil. 04/02/2013. http://portal.mpt.gov.br/wps/portal/portal_do_mpt/comunicacao/noticias/conteudo_noticia/!ut /p/c4/04_SB8K8xLLM9MSSzPy8xBz9CP0os3hH92BPJydDRwN E3cjA88QU1N3L7OgMC 93I_2CbEdFAAovLRY!/?WCM_GLOBAL_CONTEXT=\%2Fwps\%2Fwcm\%2Fconnect\%2Fm pt\%2Fportal+do+mpt\%2Fcomunicacao $\% 2$ Fnoticias $\% 2$ Fjustica+do+trabalho+condena+fund acao+florestal+em+rs+500+mi. ACESSADO EM 16/08/2013

O ESTADO DE SÃO PAULO a. Ambientalistas veem aparelhamento político em UCs de São Paulo. Por Herton Escobar e Giovana Girardi. http://www.estadao.com.br/noticias/vidae,ambientalistas-veem-aparelhamento-politico-emucs-de-sao-paulo, 1067490,0.htm. Acessado em 28/08/2013.

O ESTADO DE SÃO PAULO b. Redução da vigilância deixa unidades de conservação de São Paulo vulneráveis. Por Herton Escobar e Giovana Girardi. http://www.estadao.com.br/noticias/vidae,reducao-da-vigilancia-deixa-unidades-deconservacao-de-sp-vulneraveis, 1067486,0.htm. Acessado em 28/08/2013. 